\title{
Más allá de la defensa, la transformación. Un inventario de viejas y nuevas ideas para la Universidad pública
}

\section{HUMBERTO MÁRQUEZ COVARRUBIAS*}

\begin{abstract}
En las últimas décadas se ha emprendido una embestida estatal para convertir paulatinamente a la Universidad pública en una suerte de empresa capitalista que provea de personal, conocimiento y tecnología a las corporaciones privadas. En tanto las comunidades universitarias y sus aliados no contravengan esa ofensiva, el carácter público de la Universidad puede desaparecer, los profesores serán proletarizados y los estudiantes se tornarán en meros consumidores de servicios educativos mercantilizados. Algunas de las líneas de resistencia provienen de los procesos históricos de reforma universitaria que postulaban la independencia frente a los poderes del Estado, la Iglesia y el capital para instituir un ámbito de autonomía, democracia y libertad. Pero ya no basta erigir una defensa con talante decimonónico, sino que también se necesita impulsar una transformación de la Universidad pública para ponerla al día y contribuir al cambio social y la emancipación humana.
\end{abstract}

\section{Imperativo de definir lo alternativo}

La Universidad pública se encuentra en una verdadera encrucijada. Los gestores del neoliberalismo recortan los presupuestos destinados a la educación pública y estimulan la mercantilización de los servicios educativos mediante el cobro de colegiaturas, cuotas y servicios; promueven la colaboración de las universida-

* Docente investigador, Unidad Académica de Estudios del Desarrollo, Universidad Autónoma de Zacatecas des con las empresas privadas y fomentan el financiamiento de instancias privadas que condicionan el trabajo académico e investigativo. Mientras tanto, los lazos con la sociedad se van diluyendo.

Ante la avalancha de la contrarreforma universitaria en curso es apremiante definir el sentido alternativo de un proyecto de educación superior, que trascienda la defensa del salario y las prestaciones, y que supere las disputas de los grupos políticos que buscan ubicarse en los puestos burocráticos. Para enfrentar los desafíos de la crisis que cruza la vida de las universidades, también es impostergable que un movimiento genuino por la educación — siempre en ciernes o con vida latente - analice cuáles son las problemáticas y restricciones acerca de la educación que reciben los sectores populares y respecto de la vida social en su conjunto.

Un proyecto alternativo de educación pública universitaria tendrá que ir a contrapelo del modelo de educación de los gobiernos afectos al canon neoliberal y a las ideologías 
conservadoras. Una propuesta alternativa tiene que declararse como tal, alternativa: que en efecto se diga que se trata de una alternativa frente a la contrarreforma neoliberal en tanto proyecto dominante y que se explique en qué sentido lo es para reconstruir la Universidad necesaria del siglo XXI. ${ }^{1}$ Pero no es suficiente enunciar el predicado, hace falta darle vida al sujeto. Las propuestas educativas legítimas no surgen de los dictados de los organismos internacionales ni de las proclamas de expertos o de comités de iluminados, sino de la discusión de los directamente interesados: comunidades universitarias, investigadores, docentes y estudiantes. ${ }^{2}$

\section{Una vez más, la declaración de principios}

Autonomía

Hay que demostrar que la autonomía existe en la teoría y la práctica. Para que la vida académica pueda desplegarse de forma libre y creativa, amén de que sea capaz de formar ciudadanos participativos, críticos y humanistas, debe emitirse, ratificarse con determinación la declaración de autonomía. ${ }^{3}$ Producto de movimientos estudiantiles, la autonomía universitaria tiene un largo recorrido en el mundo. En América Latina surge con el «grito de Córdoba», en Argentina, y se despliega en sucesivos movimientos en diversos países de América Latina. ${ }^{4}$ La reforma universitaria cordobesa definió la autonomía universita-

${ }^{1}$ Pablo González Casanova, La universidad necesaria del siglo XXI, México, Era, 2000.

${ }^{2}$ Hugo Aboites, «Los movimientos estudiantiles en México y la transformación de la educación. De la lucha por las libertades y derechos civiles a la defensa y renovación de la educación pública», CISMA. Revista del Centro Telúrico de Investigaciones Teóricas, núm. 1, 2011.

${ }^{3}$ Daniel Cazés, Raúl Delgado, Axel Didriksson, Eduardo Ibarra y Javier Fuentes, «Declaración de Zacatecas», en Daniel Cazés y Raúl Delgado (coords.), Hacia una política de Estado para la Educación superior en México, México, Miguel Ángel Porrúa/ Universidad Autónoma de Zacatecas, 2003.

${ }^{4}$ Carlos Tünnermann, Noventa años de la reforma universitaria de Córdoba (1918-2008), Buenos Aires, Clacso, 2008. ria frente a los poderes del Estado, la empresa y el clero. El mayo francés de 1968 despertó una oleada de movilizaciones estudiantiles en diversas partes del mundo, incluyendo México, que generaron nuevas formas de pensamiento y prácticas políticas; unas de sus derivaciones fue la «declaración de independencia de las universidades».5 A lo largo del continente las luchas universitarias han intentado preservar y actualizar la autonomía en contextos políticos adversos como dictaduras, presidencialismos y populismos. Hoy se enfrentan a la derechización y el neoliberalismo.

Como resultado de las luchas sociales, el concepto de autonomía universitaria en México está plasmado en la Constitución (Art. $3^{\circ}$, VIII). Dicha noción se ha enriquecido con los movimientos universitarios y la propia sabiduría acumulada por las comunidades universitarias. Desde esa perspectiva, la autonomía universitaria se refiere a la capacidad y al derecho que posee una comunidad académica para elegir a sus autoridades, diseñar los planes de estudio, administrar el patrimonio, definir quiénes serán los profesores y organizarse como se considere más conveniente. ${ }^{6}$

En la actual época neoliberal está en curso una contrarreforma que acota la autonomía, cuando el Estado restringe el financiamiento, condiciona los programas educativos e impone la evaluación estandarizada. Una vez más es menester restaurarla para que sean los universitarios quienes decidan sobre las formas de gobierno, los programas educativos, el patrimonio, la legislación y la vida académica.

El ejercicio de una auténtica autonomía se traduce en una gobernabilidad democrática

\footnotetext{
${ }^{5}$ Emir Sader, Pablo Gentili y Hugo Aboites (coords.), La reforma universitaria. Desafíos y perspectivas noventa años después, Buenos Aires, Clacso, 2008; Luis Alegre y Víctor Moreno (coords.), Bolonia no existe. La destrucción de la universidad europea, Hondarribia, Hiru, 2009.

${ }^{6}$ Hugo Aboites, «La autonomía en México: entre la libertad, el Estado y el interés privado (1921-2008)», Cuadernos de Pensamiento Crítico Latinoamericano, núm. 13, 2008.
} 


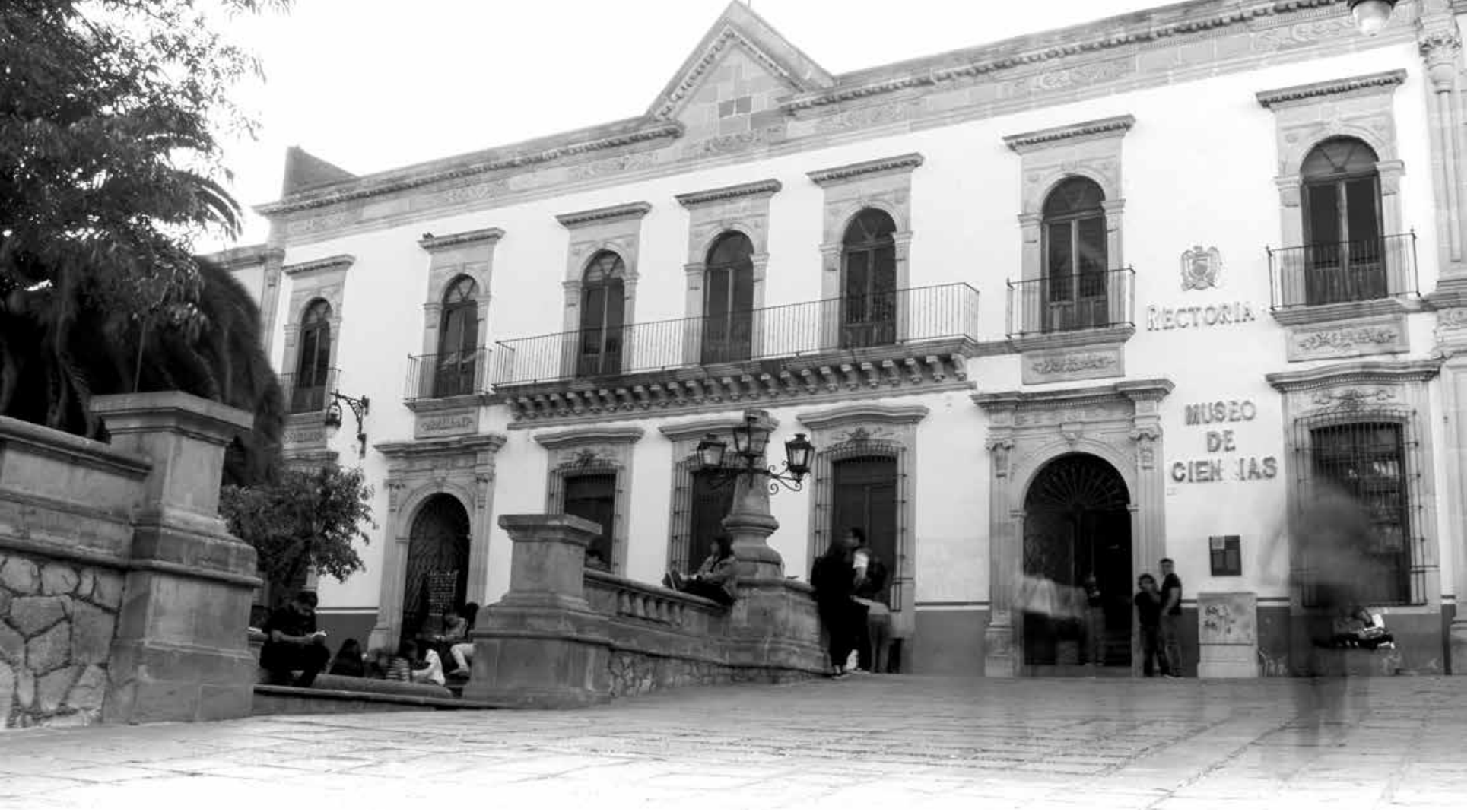

construida desde adentro, donde la máxima autoridad no sea la burocracia ni las agencias gubernamentales e internacionales empecinadas en implantar la contrarreforma, sino las instancias colegiadas compuestas por profesores y estudiantes. Sin embargo, en la mayoría de las universidades los consejos universitarios, máximos órganos de gobierno, tienen una composición tripartita: profesores, estudiantes y funcionarios, lo cual obra a favor de la rectoría, pues los funcionarios votan en bloque, mientras que los profesores y estudiantes lo hacen de manera diferenciada. Entonces, se impone el poder de un bloque burocrático cuya misión es ampliar sus espacios de poder y control sobre los demás sectores, con lo que se adoptan y perpetúan las prácticas perversas de la política del sistema de partidos.

Instalar formas de gobierno democrático es una condición necesaria para restablecer la autonomía universitaria. En los consejos universitarios, por ejemplo, el número de escaños puede distribuirse entre profesores y estudiantes con sólo un funcionario, el rector, para hacer posible que la discusión acerca de normas, presupuestos y proyectos tenga lugar entre ambas partes y las decisiones sean legítimas y se apeguen a los intereses de la comunidad.?

\section{Autogobierno}

Distintas políticas y dispositivos se implementan para trastocar la vida académica de las universidades al valorar a los espacios administrativos como cabeza de playa a fin de que sean los universitarios, a partir de los grupos políticos hegemónicos, quienes internalicen la norma educativa neoliberal. Entonces la actividad académica muta su compromiso social por el individualismo, el productivismo y la competencia. El catálogo de nuevos valores es asimilado en la vida orgánica y trastoca los criterios básicos de la política de las universidades. ${ }^{8}$

Las instancias colegiadas y el trabajo colectivo que busca responder a las directrices de evaluadores externos, a menudo instancias

${ }^{7}$ Orlando Pardo, «Democracia y gobierno en la universidad», Reflexión Política, vol. 5, núm. 10, 2003.

${ }^{8}$ Humberto Márquez, «Nubarrones en el jardín del conocimiento. La universidad pública bajo el asedio estatal», Estudios Críticos del Desarrollo, vol. vi, núm. 10, 2016.
Instalar formas de gobierno democrático es una condición necesaria para restablecer la autonomía universitaria. Fotografía: Carlo Román 
privadas que cobran por sus servicios, aplican formularios o pruebas con pautas estandarizadas y armonizadas con el mercado y extienden certificados que serán reconocidos para acceder a ciertos programas de financiamiento. En esas condiciones la autonomía está acotada por las formas de evaluación que limitan el acceso a los recursos necesarios para su funcionamiento. En paralelo, dentro de las universidades se especializan gestores emanados de los grupos políticos, que con distintos discursos se disputan los puestos internos de administración y poder, pero terminan siendo funcionales a la proclama general de la contrarreforma universitaria, ya que en tanto gestores se especializan en la administración de la crisis universitaria. Bajo esa pauta permiten la intromisión del programa neoliberal: reestructuración administrativa y educativa, promulgación de la austeridad y el decrecimiento, aceptación de la exclusión de estudiantes y la precarización del trabajo. ${ }^{9}$

Esta forma de conducción puede ser sobrellevada, más allá de las formas de resistencia que reiteran métodos de lucha tradicionales y no muy efectivos, como paros, manifestaciones y huelgas, hacia una transformación de las universidades en un espacio controlado y administrado desde afuera y desde adentro por un bloque de poder burocrático que promueve e implementa la contrarreforma educativa.

La reconstrucción de una gobernabilidad alternativa se refiere a la recreación de formas de autogobierno con principios democráticos, con base en normas y reglas claras establecidas por la comunidad universitaria. ${ }^{10}$ No se trata de una política de confrontación y desgaste sino de una reconstrucción de la misión social de la Universidad pública y de un reposicionamiento de

\footnotetext{
${ }^{9}$ Humberto Márquez, «Universidad pública intervenida. Subsunción del trabajo conceptual y desvalorización del proceso educativo», Observatorio del Desarrollo, vol. 6, núm. 16, 2017. ${ }^{10}$ Enrique González Rojo, «Acerca del autogobierno en las universidades», Coloquio Autonomía, Educación y Libertad, Universidad Autónoma de la Ciudad de México, 20 y 21 de noviembre de 2012.
}

la educación pública superior en el entramado institucional al servicio de la comunidad.

\section{Fortalecimiento institucional y estatuto de legalidad}

El autogobierno tiene que asentar la institucionalidad universitaria con una sólida legalidad, es decir, normas donde se establecen obligaciones mutuas para el cumplimiento del proyecto universitario desde un marco transparente, que ayude a orientar el camino de todos los sectores que conforman la comunidad universitaria. La legalidad puede abrir puertas, trazar horizontes y garantizar un marco de libertad a las comunidades para organizarse en el ámbito de la autonomía. ${ }^{11}$ Las reglas del juego deben determinarse con toda claridad, pero sólo en la medida de lo necesario, para no ahogar la creatividad y someterse a formas autoritarias y restrictivas, lo cual sería contraproducente. A sabiendas de que la sobrerregulación puede aniquilar la creatividad y la participación, un marco legal deseable es aquel que aclara el funcionamiento, los derechos y las posibilidades de participación de cada quien.

\section{Democracia}

Otro aspecto igualmente importante es la democracia. La idea de que en la Universidad - y en general en la vida académica no existe, no puede hacerlo - la democracia está más o menos arraigada, proviene de prácticas decimonónicas que perviven en prácticas y ritos académicos contemporáneos modelados por órdenes jerárquicos, pero que no son asequibles para un proyecto alternativo de educación superior. Todos los sectores que integran la vida académica pueden y deben participar, en la medida de sus intereses, posibilidades y obligaciones. En los ámbitos de decisión institucional cabe la participación para

\footnotetext{
${ }^{11}$ Adrián Acosta, «La autonomía universitaria en América Latina: problemas, desafíos y temas capitales», Universidades, núm. 36, 2008.
} 
decidir sobre el patrimonio, el presupuesto y los proyectos estratégicos, los programas educativos y las prácticas pedagógicas, la contribución a la sociedad, etcétera. Asimismo, no tienen cabida las formas autoritarias, unipersonales y el nepotismo como modos de ejercer el poder en los distintos niveles y planos de las instituciones educativas. Esto se complementa con la erradicación de la corrupción y la opacidad.

\section{Ética crítica}

Indiscutiblemente, el sistema educativo y el conocimiento representan instancias fundamentales para impulsar procesos de transformación. Con ese propósito se impone la necesidad de reivindicar un sentido ético profundo para la vida pública y la vida universitaria.

En una sociedad donde la clase dirigente practica la corrupción como mecanismo de enriquecimiento y acceso a las instancias de decisión, y pretende justificarlo al aducir que es una cultura arraigada en la sociedad, y donde además la sociedad padece diferentes tipos de decadencia que laceran las relaciones sociales, las instituciones y las formas de gobierno, es imprescindible alentar un proyecto de cambio social impregnado de un profundo sentido ético. ${ }^{12}$

Un cambio de esta magnitud no podrá realizarse, porque no interesa, desde las altas esferas del poder político y económico, ni es de esperarse que acontezca una renovación moral de la clase política, donde confluyen los políticos profesionales, los intelectuales del régimen, la jerarquía eclesial, los medios de comunicación, la burocracia y la academia convencional.

Eventualmente, un cambio sustancial puede articularse desde las bases sociales en las que perviven instancias como sindicatos, gremios, movimientos sociales y diversas organizaciones sociales interesadas en encontrar alternativas desde la práctica.

\footnotetext{
${ }^{12}$ Enrique Dussel, 14 tesis de ética. Hacia la esencia del pensamiento crítico, Madrid, Trotta, 2016.
}

Cualquier proyecto o movimiento social que pretenda impulsar la transformación requiere, por necesidad, pensar y actuar con sentido ético, y también transmitir un mensaje ético. Reconstruir la Universidad amerita buscar las raíces éticas de la figura peculiar que representa la Universidad pública. Requiere un trabajo de reconstrucción histórica para desenterrarla y plantearla claramente a la sociedad como proyecto presente y futuro.

En este momento crucial, signado por varias expresiones de crisis en el Estado, el medio ambiente y las relaciones sociales, la Universidad pública puede plantear una postura ética que emerja de su misión educativa y cultural, de su enraizamiento y compromiso con la parte más débil de la sociedad: trabajadores, pobres, migrantes, indígenas, niños, jóvenes y comunidades apartadas.

\section{Pensamiento crítico, autocrítica \\ $y$ debate de alternativas}

Un ámbito privilegiado para el análisis y la discusión de los problemas sociales y el debate sobre las alternativas es la Universidad pública. Este espacio tiene la capacidad y la obligación de elaborar propuestas viables de desarrollo humano articuladas con los sectores de la sociedad organizada. Así como no hay democracia sin demócratas, no hay transformación social sin transformación de los sujetos. Por lo que una premisa del cambio es cambiar a los proponentes del cambio para que desde un sentido autocrítico también discutan y acuerden actualizaciones al papel de la Universidad pública.

Los universitarios pueden proponer la transformación de la sociedad en general y también ser autocríticos para transformar a la Universidad pública, desde la vida institucional y las prácticas académicas hasta las contribuciones al desarrollo de la sociedad. 
Inclusión socialy opción por los pobres

El precepto básico de la educación pública es que todos los estudiantes tienen derecho a ingresar a una institución de educación, independientemente de su condición social, edad o género. Esta es la piedra angular de un proyecto transformador.

Actualmente, la mayoría de los jóvenes está relegada de los estudios universitarios. En ello influyen factores como el cierre del acceso a los programas educativos, pues se aplican exámenes de selección que actúan como filtros para estrechar el paso y seleccionar a un porcentaje menor de solicitantes, con lo cual se niega de facto el derecho a la educación. Otro filtro es el costo de manutención y los cobros de colegiaturas, cuotas, materiales y servicios. Hay carreras que son decididamente prohibitivas para estudiantes pobres; no tiene caso siquiera intentar postular el ingreso. Un Estado social debe garantizar el derecho a ingresar directamente a las aulas a los estudiantes egresados de los niveles previos o buscar opciones para su acomodo, así sea en el ciclo en que se solicita o en uno posterior. ${ }^{13}$

\section{Gratuidad de la educación}

La homologación de las pautas del mercado en el proyecto educativo, sobre todo a nivel superior, convierte al estudiante en un consumidor de servicios educativos que busca en el mercado las opciones que le ofrecen las instituciones públicas y privadas, las cuales, por su parte, se esmeran en ofrecer un amplio menú de carreras técnicas, profesionalizantes y acordes con las ofertas laborales emergentes, además de mantener el núcleo básico de carreras tradicionales que han distinguido históricamente a las universidades. La competencia en el mercado de servicios educativos es la pulsión del proyecto educativo en boga.

${ }^{13}$ Humberto Márquez, «Asalto a la razón: estrangulamiento de la universidad pública», Observatorio del Desarrollo, vol. 5, núm. 15, 2016.
Los aspirantes a ingresar a, pero también los que necesitan permanecer en, la educación superior se enfrentan al desafío de no sólo cubrir su vocación o interés educativo sino también de afrontar la exigencia de pagar cuotas de ingreso y colegiaturas, sufragar gastos de manutención y otros que cada una de las carreras precisa: desde los gastos ordinarios como hospedaje, alimentación y transporte, pasando por la adquisición de bibliografía, hasta equipos de computo, consumibles e instrumental para prácticas, según los requerimientos.

En un contexto donde la condición de pobreza se ha generalizado, la mayoría de los jóvenes aspirantes no cuenta con el respaldo familiar e institucional para solicitar un lugar en el sistema educativo. Más aún, la mayoría de las universidades, a través de sus programas educativos, no ofrece plazas suficientes para el número de aspirantes. Con ella se cierra la espiral de exclusión educativa y se diluye todo esfuerzo institucional de satisfacer la formación integral de la juventud aspirante.

Desde el punto de vista de un proyecto alternativo que conecte la educación con el desarrollo humano, la condición socioeconómica no debe ser un impedimento para asistir a una universidad. Es obligación del Estado generar las condiciones institucionales que garanticen educación pública para toda la población que así lo requiera. Desde esa óptica, la Universidad pública debe ser gratuita, en todos los niveles, para toda la población, independientemente de la clase social, el género, la etnia y la edad. En lugar de promover bonos que incentivan la educación privada, en detrimento de la consolidación del sistema público, el Estado debe subsanar las desigualdades sociales y ofrecer becas y otros apoyos a los estudiantes, de manera equitativa si fuera posible, sin que la condición socioeconómica fuese un requisito. Quienes cubren ciertos requisitos tiene el derecho a una beca. 


\section{Pedagogía crítica}

Las relaciones de enseñanza-aprendizaje no pueden sustentarse en vínculos autoritarios dentro y fuera del aula. Las relaciones de poder donde el profesor es la máxima autoridad incuestionable y el estudiante es un receptor pasivo son esquemas del pasado que perviven en el presente. Otra propuesta pedagógica es imprescindible, pues en el proceso de enseñanza-aprendizaje está la relación básica de cualquier proyecto educativo. Al interior del aula deben ensayarse cambios. Si dentro de la institución se toman decisiones autónomas, participativas, democráticas, pero en el aula el maestro es un pequeño dictador, que trata a los estudiantes como súbditos, cualquier proyecto con pretensiones alternativas se irá por la borda. El cometido es emancipar dentro del vínculo pedagógico a los jóvenes, a los niños, mediante el conocimiento y la participación como aspectos fundamentales del proceso educativo, para aprender a ser independientes, no a memorizar. ${ }^{14}$

En una relación pedagógica libertaria, crítica y creativa, todas las partes, maestros y estudiantes, aprenden y dialogan. Además, en los niveles educativos superiores se pueden conformar comunidades de investigación a fin de otorgarle un sentido más profundo al programa educativo y al trabajo colectivo referente al estudio de problemas importantes de la vida social. Más allá de la generación de títulos, certificados y productos académicos, las formas de trabajo colectivo en el ámbito de investigación, reflexión y análisis carecen de fecha de caducidad y no se supeditan a mecanismos de regulación burocrática. Están llamados a colaborar estudiantes, profesores y egresados, además de miembros de diversas áreas y disciplinas, instituciones y centros de investigación, sin importar adscripciones y reconocimientos. Pueden ser modos de articulación

${ }^{14}$ Enrique Dussel, «La organización de la comunidad de estudiantes», La Jornada, 10 de abril de 2000, en http://www. jornada.unam.mx/2000/04/10/dussel.html permanentes donde se analicen temas de interés compartido. ${ }^{15}$

\section{El fin justifica los medios}

\section{Financiamiento suficiente}

El Estado ha sometido y condicionado el funcionamiento de las universidades al restringirles el financiamiento, reestructurar sus programas, evaluar su desempeño y precarizar a los trabajadores. ${ }^{16}$ El poder se ejerce desde un mando burocrático que encuentra un alma gemela en grupos internos de poder que se burocratizan y aplican acríticamente las determinaciones estatales. De manera que el Estado estrangula, interviene y condiciona a las universidades. Sin embargo, las universidades tienen la capacidad de ser un referente ético de la sociedad para observar, evaluar y auditar el desempeño de los gobernantes, los políticos profesionales, las políticas públicas y la burocracia.

\section{Relación independiente con el Estado}

La relación con el Estado, o en específico con las instancias gubernamentales encargadas de organizar y financiar la educación pública, es un punto de partida imprescindible, que habitualmente se bifurca entre el control burocrático y la búsqueda de autonomía. Desde el punto de vista oficial de los gobiernos neoliberales, la Universidad debe orientarse bajo preceptos empresariales, al igual que se visualiza a la administración pública. ${ }^{17}$ No obstante, está claro que la escuela no es una empresa y no puede regirse bajo normas neoliberales: individualismo, competencia,

\footnotetext{
${ }^{15}$ Hugo Zemelman, Voluntad de conocer. El sujeto y su pensamiento en el paradigma crítico, Barcelona, Anthropos, 2005. ${ }^{16}$ Eduardo Ibarra, «Efectos institucionales de las politicas de modernización universitaria en México: autonomía, gobernabilidad y nuevas formas de organización», en Daniel Cazés y Raúl Delgado (coords.), op. cit.

${ }^{17}$ Christian Laval, La escuela no es una empresa: el ataque neoliberal a la enseñanza pública, Barcelona, Paidós, 2004.
} 


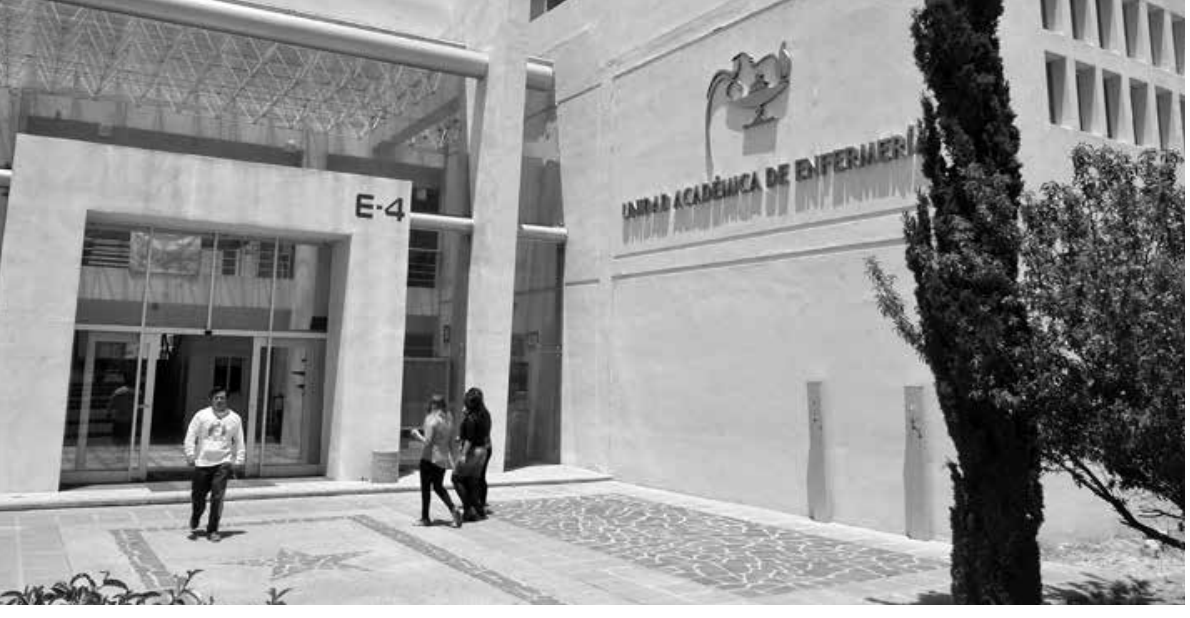

La fragmentación perniciosa del conocimiento en áreas, disciplinas y especialidades dispersas demerita el trabajo colectivo entre investigadores y docentes, además propicia que el conocimiento generado sea particularista o inconexo. Fotografía: Jorge Vázquez venta de servicios, austeridad presupuestal y exclusión de estudiantes económicamente insolventes.

Si la noción de Estado se acerca a una forma del ejercicio de gobierno donde se imponen los criterios de una elite social, de talante oligárquico, entonces se advierte una especie de desencajamiento de la educación y sus instituciones con el proyecto político del Estado y se imponen los financiamientos restrictivos y condicionados, los programas educativos basados en competencias y la formación de estudiantes como capital humano, valga decir fuerza de trabajo dúctil, empleable.

Pero si el Estado se afirma como un espacio político donde cabemos todos, sin estadolatrías, entonces la educación adquiere otro talante, la piedra de toque de un genuino desarrollo humano. En tal caso se advierte la necesidad del financiamiento suficiente y oportuno para el sistema de educación pública en su conjunto. ${ }^{18}$

Asimismo, en lugar de que la educación pública, y en particular la Universidad pública, esté bajo acoso permanente de la burocracia estatal, los universitarios deberían de levantar cabeza para erigirse - como otras áreas de la actividad humana que ya lo hacen, o también pueden hacerlo - en la conciencia crítica de la sociedad, con la finalidad de evaluar y criticar el funcionamiento del Estado y sus diversas instancias operativas, programas y ejercicios presupuestales. La simbiosis entre investigación y

${ }^{18}$ Axel Didriksson, «Elementos para la construcción de una política de Estado en la educación superior», en Daniel Cazés y Raúl Delgado (coords.), op. cit. desarrollo puede tomar como eje la gestión estatal del desarrollo y el modelo de desarrollo nacional y local, con sus conexiones internacionales, para advertir problemas, potencialidades y alternativas de gran calado. A su vez, en el marco de la autonomía, las universidades tienen que evaluar, en su momento, cuáles son los alcances y los límites de la relación con el Estado, en concreto con las instancias gubernamentales y con organismos sociales, nacionales e internacionales que pretenden incidir en el devenir del proyecto educativo; esto permitirá dilucidar qué se puede hacer con y sin ellos.

En contrasentido a la relación de dependencia que teje el Estado, los universitarios pueden configurar un proyecto educativo alternativo desde un ámbito de independencia. Eventualmente, ante la pregunta de hasta dónde ir y hasta dónde no con el Estado, las propias comunidades universitarias, en su contexto y momento, podrán encontrar las respuestas adecuadas. ${ }^{19}$ Algunas experiencias radicales de educación optan por no ir con el Estado, bajo ninguna circunstancia; otras más afirman su autonomía pero no niegan la posibilidad de contribuir con el Estado en la medida en que cumplan objetivos de desarrollo social; otras más aceptan el condicionamiento estatal y las prescripciones privativas.

\section{Calidad educativa y eficiencia}

El criterio de calidad educativa se ha reducido a la aplicación de programas educativos prediseñados por organismos internacionales desde la visión consensuada por tecnócratas y expertos afines al proyecto neoliberal y globalizado. Asimismo, se ajusta a formas de administración de los recursos, el patrimonio y la actividad académica cercanas a la tónica de la austeridad presupuestal, que es un modo de acompasar la reducción del gasto público en educación y otros

\footnotetext{
${ }^{19}$ Carlos Tünnermann, «La autonomía universitaria en el contexto actual», Universidades, núm. 36, 2008.
} 
capítulos generales del desarrollo social con la manera de promover la educación cercana a las pautas del mercado. Aunado a ello, se asumen los criterios de evaluación de la calidad educativa sustentados en indicadores de desempeño que cuantifican rubros como la eficiencia terminal, la bibliometría (número de artículos, libros, capítulos y ponencias), entre otros, para mejorar, a su vez, los indicadores internacionales de la educación. No se puede negar que ciertos indicadores son útiles y necesarios, pero no son suficientes, ni siquiera significativos para una misión social con profundo contenido educativo y de desarrollo humano. La compulsión cuantitativa no define por sí sola la calidad educativa.

La calidad no es la obtención de un título ni tener altas tasas de egresados ni una planta docente muy productiva, sino la formación integral de los estudiantes, la formación de una ciudadanía universitaria, la integración de la universidad con la sociedad, la generación de conocimiento relevante para el desarrollo humano, la promoción de la cultura y las artes. ${ }^{20}$ Actividades como estas no necesariamente se miden y escapan a la revisión de evaluadores externos que siguen otros criterios. Cuánto contribuye la educación superior al desarrollo humano en un espacio social concreto, sea local, nacional o internacional, es uno de los referentes básicos dentro de la configuración alternativa.

El criterio de calidad debe estar presente en un modelo alternativo, pero en otras coordenadas. Se trata de ofrecer educación fundamentada en la investigación científica y en formas de pensamiento pertinentes para el desarrollo generalizado desde una propuesta educativa que permita que niños y jóvenes avancen en su formación integral. Es posible cumplir objetivos concretos de los programas educativos y simultáneamente formarlos con una visión humanista, científica y crítica. La amplitud de la oferta en las carreras y profesiones, en espacios de encuentro y diá-

\footnotetext{
${ }^{20}$ Pablo González Casanova, op. cit.
}

logo entre formas de conocimiento y diversas prácticas educativas, puede conjugarse con la formación plena de ciudadanos participativos y dinámicos en el marco del ejercicio libertario y autonómico de la actividad universitaria.

\section{Universidad extramuros}

La división tajante entre un ámbito interno y otro externo de la universidad es una falsa representación de su vida orgánica, que siempre está, o debería estar, abierta a la sociedad. A ello contribuye la imagen de que los académicos se encierran en su torre de marfil y de que los estudiantes cumplan labores en el aula con el objeto de aprobar materias y acceder a un certificado o título que les dará reconocimiento para enfrentar luego el mundo real donde, quizá, aprenderán a ejercer su profesión y pondrán a prueba sus conocimientos.

\section{Universidad como espacio común}

Como un producto social, la Universidad pública se ha formado, en algunos casos, como un espacio de inclusión educativa para los sectores populares y además ha permitido el despliegue del pensamiento crítico, la ciencia, la cultura y las artes con una vocación social. Sin embargo, con la acogida neoliberal y sus formas de pensamiento único, convencional y neoconservador, el cariz popular, crítico y social se revierte hasta el punto en que se privilegia una subjetividad individualista, emprendedora y mercadológica. Pareciera que el presente y futuro de la Universidad quedará postrado entre la defensa de lo público y lo privado, con alusión a lo estatal y a lo empresarial, o una combinación de ambos componentes.

Más allá de esa tensión, la Universidad pública puede configurarse como un espacio común donde los miembros de la comunidad universitaria se organizan, establecen sus normas y forma de gobiernos, fijan sus agendas de trabajo y determinan los programas de estudio, investigación, 
docencia, divulgación y otras actividades sustantivas. No se trata de que la Universidad se vea como un mero bien común, como un ámbito peculiar sujeto a apropiación de grupos políticos, burocracias, elites académicas y fuerzas internas que se distribuyen los espacios internos y sus recursos, sino de que se recreen comunidades activas bajo preceptos democráticos y participativos, formas de autogobierno que hagan posible, a su vez, reinsertar a la Universidad dentro de la comunidad humana, de donde nunca ha salido, pero se ha distanciado, para contribuir al despliegue de la democracia, el bienestar social y el buen vivir.

\section{La Universidad como agente de desarrollo}

La noción de desarrollo ha sido objeto de numerosas y merecidas críticas, sobre todo la que está articulada con visiones e intereses del capital monopolista y los Estados represores que estimulan la actividad depredadora de la naturaleza, la explotación redoblada de los trabajadores, la violencia generalizada y el empobrecimiento de la mayoría de la población. No obstante, existen otras nociones de desarrollo, que en distintos términos expresan la necesidad de acompasar la capacidad social productiva auspiciada por tecnología, conocimiento, infraestructuras con las probabilidades de satisfacer las necesidades sociales (no lo hacen porque se venden como mercancías y sólo acceden a ellas quienes pagan); así como la urgencia de generar condiciones de vida que permitan no sólo la satisfacción de las necesidades básicas de la población sino el despliegue de las capacidades humanas que cualquier persona puede llevar a cabo en el ámbito personal, científico, artístico y cultural.

A lo anterior se le denomina, en términos genéricos, desarrollo humano. Es preciso aclarar que el concepto mismo también puede ser sometido a crítica, en especial cuando es planteado desde la visión liberal social para alentar un cierto individualismo, un desarrollo humano de perso- nas que, en cualquier contexto y lugar, sin cuestionar el capitalismo y sus formas políticas como el neoliberalismo, puede lograrlo en cuanto a longevidad, salud, educación y rubros semejantes.

Esta propuesta es notoriamente insuficiente porque es imposible que en el capitalismo se promueva el desarrollo humano generalizado, lo que en realidad se impulsa es el desarrollo desigual, entre regiones y clases sociales. Pero un desarrollo humano, o una expresión nombrada bajo otro término (Vivir Bien, economía de la vida, común, etcétera) es factible y amerita un cambio social. En ello la Universidad pública tiene la obligación de cumplir un papel fundamental. No sólo como productora de títulos, certificados y reconocimiento, o de gestora de conocimiento, ciencia y tecnología, o de promotora de la cultura y el arte, actividades importantes que al ser enmarcadas en la «economía de mercado» se canalizan hacia fines privados de rentabilidad y procesos acusados de diferenciación social.

\section{Cumplir los fines es apenas el comienzo}

\section{Formación de una ciudadanía universitaria}

La política educativa actual, preñada de preceptos neoliberales, promueve la precarización de las condiciones de trabajo y de vida de docentes, investigadores, administrativos y otras categorías laborales. En adición, incentiva una mentalidad individualista y la competencia entre colegas, lo cual deteriora la cooperación y la solidaridad y desencadena conflictos internos como forma de hacer política para disputarse los cargos administrativos y los recursos disponibles. El trabajo docente se degrada, pues en lugar de representar una actividad intelectual vinculada a la investigación se reduce a una función técnica. La competencia incluso se fomenta para acceder a ingresos suplementarios con la evaluación del desempeño académico mediante puntos, a fin de ser reconocidos como investigadores y docentes. 
Esta competitividad se inmiscuye en una espiral descendente de la vida institucional y de la pertinencia social de trabajo universitario.

La estratificación de los trabajadores académicos por productividad, puntos y reconocimientos se traduce en una diferenciación salarial y en un estímulo al individualismo y la competitividad galopante. La dignificación del trabajo académico en todos los niveles mediante salarios y prestaciones dignos, sindicalismo democrático y la ruptura del control burocrático son aspectos básicos para conferirle un renovado rostro. En un escenario ideal, el personal docente pudiera ganar un salario suficiente, digno y seguro, sin las sujeciones de la evaluaciones competitivas e individualistas, sin categorías diferenciadoras ni carreras magisteriales sin evaluación por puntos, sin becas ni estímulos productivistas, sin importar el tiempo, la experiencia y la edad de profesores e investigadores.

\section{Formación integral de jóvenes}

El desempleo estructural, derivado del ahorro de fuerza de trabajo por nuevas tecnologías, la desvalorización de las profesiones y carreras universitarias por la flexibilización del mercado laboral y el recorte al financiamiento público de la educación actúan como fuerzas que constriñen el acceso a la educación pública superior de calidad para la mayoría de la población. El impacto más pernicioso es el efecto combinado de la formación de generaciones con altos estudios pero sin trabajo formal o acorde a su perfil educativo y, simultáneamente, la procreación de una gran masa de jóvenes precarizados que padecen exclusión de las instancias educativas o del mundo del mercado, lo cual no es muy preciso, pues muchos sobreviven en actividades informales, incluyendo actividades peligrosas e ilícitas, o emigran para trabajar en otras latitudes.

La Universidad pública debe recrear los espacios formativos, los programas educativos y las prácticas pedagógicas con la finalidad de formar nuevas generaciones de estudiantes, profesionis- tas, investigadores e intelectuales que dentro y fuera de la esfera educativa reconstruyan las formas del trabajo social y las actividades colectivas que obren en beneficio del desarrollo humano generalizado.

\section{Compromiso social}

La sociedad capitalista promueve la competencia desbordada en todos los planos: entre clases sociales y dentro de ellas para distribuirse el plusvalor o excedente generado por el trabajo social. La competencia es el principio articulador de la sociedad capitalista. La internacionalización de la competencia desvirtúa la misión de la Universidad pública, a menos que se pretenda erigir la Universidad capitalista como una empresa.

El compromiso social escapa a las normas del mercado, la competencia y la búsqueda de ganancia, para servir a los intereses de clases, movimientos y comunidades concretos con la intención de promover una mejoría sustancial en sus condiciones de vida y trabajo. Amén de buscar el beneficio de las comunidades a través del conocimiento y la cultura. En un plano inmediato, la comunidad universitaria puede recuperar los lazos con las comunidades circundantes en su diversa constitución, lo cual hace factible un desdoblamiento hacia fuera para incidir en la mejoría concreta desde el conocimiento y la cultura en las comunidades concretas locales y nacionales, en el barrio, la zona, la región y el país. Asimismo, es digno reconocer que en todas las comunidades hay procesos de conocimiento y la Universidad puede contribuir a mejorarlos, a partir de respetar su condición política y organizativa, la conciencia personal y humana; es decir, la sustancia significante de clases, comunidades y sectores sociales.

Generación de conocimiento

de utilidad social

La fragmentación perniciosa del conocimiento en áreas, disciplinas y especialidades dispersas 
demerita el trabajo colectivo entre investigadores y docentes y propicia que el conocimiento generado sea particularista o inconexo y a la postre los productos son crípticos, privatizados; por lo tanto se oscurece el conocimiento social. ${ }^{21}$ La llamada sociedad del conocimiento promueve la idea de que el conocimiento es un estímulo para la producción y la obtención de beneficio privado. En tal caso, el conocimiento se torna en una mera mercancía, en cuya trayectoria de gestación, divulgación, industrialización y comercialización se incuban rentas, formas de ganancia extraordinaria generadas por la posesión ejercida en exclusividad de los productos de la ciencia y la tecnología con la aplicación de trabajo vivo, en particular del trabajo conceptual, intelectual o general, que de ser una potencia social se convierte en una fuerza aplicada a la órbita de los negocios; entonces la ciencia se torna en capital. En contrasentido, el conocimiento puede configurarse como una potencia social inapreciable a condición de que sea libre, crítico y propositivo. Por lo mismo, la Universidad pública puede fungir como agente catalizador de una función social del conocimiento con el interés de transformar a la sociedad.

\section{Proyecto educativo y desarrollo generalizado}

Cualquiera que sea la solución propuesta para la defensa y transformación de la Universidad, ésta será inviable y muy limitada si se conduce por una pauta individualista, es decir, si se remite a una institución en particular, un programa educativo, un centro de investigación o un grupo selecto de académicos. La respuesta es estructural y sistémica. Compete al conjunto de las universidades y, más aún, al sistema educativo dentro de un determinado proyecto nacional. La Universidad no se rescata, se defiende o se transforma a sí misma, de forma aislada; lo hace junto con todo el entramado socioeco-

${ }^{21}$ Pablo González Casanova, Las nuevas ciencias y las humanidades, Barcelona, Anthropos, 2005. nómico en el que se inserta, porque su supervivencia depende de ello y su servicio o misión social corresponde al conjunto social.

\section{Formas de nombrar a la Universidad necesaria}

La Universidad es una fuerza social productiva que puede usarse en beneficio de la sociedad en general y de sectores específicos, de conformidad a sus necesidades y potencialidades dentro de un proyecto de transformación social sustantiva. También puede ser una potencia productiva que tienda a servir a las empresas cuya pretensión es obtener ganancias sin observar la estela de destrucción y descomposición causadas por esos «daños colaterales» o «externalidades». En términos sociales puede tornarse una fuerza contraproductiva. ${ }^{22}$

Decidir sobre la orientación del conocimiento, las tecnologías, las formaciones educativas y las actividades universitarias es una tarea que incumbe a las comunidades autónomas y a la par es un asunto de interés social. La toma de decisiones no puede quedar encapsulada en los bloques de poder burocrático-político que operan dentro y fuera de las universidades; se trata de una tarea que amerita la reflexión y el análisis de amplios sectores sociales, desde trabajadores y estudiantes hasta movimientos, sindicatos, partidos y organizaciones sociales interesados en promover un auténtico desarrollo humano.

La Universidad incuba el intelecto general (General Intellect), ${ }^{23}$ es decir, los conocimientos y saberes que partiendo de la abstracción, del trabajo científico, se convierten en bienes públicos; el conocimiento abstracto se torna entonces en forma empírica, en potencia económica y en sentido común. Sin embargo, esta traslación,

\footnotetext{
${ }^{22}$ Iván Illich, La sociedad desescolarizada, Barcelona, Barral, 1974.

${ }^{23}$ Karl Marx, Elementos fundamentales para la crítica de la economía política (Grundrisse) 1857-1858, vol. 2, México, Siglo XXI, 1980.
} 
conversión o adopción del conocimiento abstracto en hecho empírico no es un movimiento puro y alejado de conflictos; al contrario, constituye un momento crítico de la validación social del trabajo universitario. Existen otros modelos del conocimiento que pretenden deformar, negar o apropiarse del conocimiento científico. Por ejemplo, ideólogos, teólogos, comunicadores y publicistas al servicio del poder divulgan informaciones y noticias que falsean u ocultan los hechos para que persista una verdad, la que conviene al poder; si la verdad científica no coincide, peor para ella, la ciencia está equivocada. Además, están quienes desean apropiarse del conocimiento generado por el trabajo colectivo de los universitarios e investigadores para privatizarlo, condicionar su uso, patentarlo y transformarlo en mercancía. El desafío es que esa masa crítica de conocimiento, información, ideas y proyectos generados por los universitarios esté al servicio preferente de la sociedad, de sectores concretos, sobre todo de las clases más necesitadas, pauperizadas, explotadas y despojadas. Cuando el Estado y el capital median o instrumentalizan ese conocimiento, habitualmente lo hacen con otros propósitos de dominación, control, explotación y enriquecimiento.

La Universidad forma el trabajo conceptual, general o intelectual: científicos, tecnólogos, intelectuales, artistas, escritores, creadores y políticos. Ámbitos de la actividad humana en la que predomina la capacidad de criticar, proponer y crear en distintos órdenes de la vida económica, social, política y cultural. Tampoco detenta el monopolio del conocimiento y el saber. Pero tiene que entablar diálogo respetuoso y crítico con otros ámbitos de conocimiento y otras formas de pensamiento. ${ }^{24}$ La Universidad no puede permanecer como un espacio que reproduce y amplifica la ideología dominante y el discurso del poder, que a menudo aparece entreverado en los discursos académicos, en las intenciones de

\footnotetext{
${ }^{24}$ Boaventura Sousa Santos, La universidad en el siglo XXI,
} México, Siglo XXI, 2015. los proyectos de investigación, en los programas de reestructuración administrativa y académica.

Un mínimo de congruencia ética y de sentido autocrítico plantea a los universitarios una carta de navegación como antídoto de las prácticas del poder que cuestiona: si reclaman la democratización de la sociedad, deben observar la democracia en la vida universitaria; si reclaman la abolición de la corrupción en la política y los negocios, también deben hacer lo propio dentro de la institucionalidad universitaria; si reclaman transparencia y rendición de cuentas en las instancias estatales, tienen que plantear algo semejante para las instituciones educativas; si cuestionan la práctica del nepotismo y el uso patrimonialista de recursos públicos, a su vez están obligados a ser rigurosos en el manejo de recursos universitarios y la contratación de personal; si cuestionan la intromisión de intereses privados para la apropiación de bienes y servicios públicos, de manera correlativa es apremiante que realicen el escrutinio del financiamiento privado y la contravención de normas corporativas en las universidades públicas en aras de la defensa de lo público; si exigen la mejora del salario y prestaciones de los trabajadores de las universidades, por añadidura están obligados a ser solidarios con las condiciones de vida y trabajo de otros sectores laborales precarizados.

La Universidad pública es un espacio común, una casa abierta. Para escapar a la pretensión de que la educación sea una empresa, que los estudiantes compitan, que los profesores se precaricen y que todo se convierta en una forma de mercado de servicios educativos; para escapar del estrangulamiento estatal, del condicionamiento a obtener recursos si se reestructuran y aceptan la norma mercantil, los universitarios tienen la capacidad política de reconfigurarse, ir más allá de la proclama de defensa de la Universidad pública y avanzar hacia la configuración de lo común universitario, de la puesta en común de la Universidad para servir a la transformación social sustantiva. 